\title{
Glucose production, gluconeogenesis, and hepatic tricarboxylic acid cycle fluxes measured by nuclear magnetic resonance analysis of a single glucose derivative
}

\author{
Eunsook S. Jin, ${ }^{a}$ John G. Jones, ${ }^{\mathrm{b}}$ Matthew Merritt, ${ }^{\mathrm{a}}$ Shawn C. Burgess, \\ Craig R. Malloy, ${ }^{a, c}$ and A. Dean Sherry ${ }^{\mathrm{a}, \mathrm{d}, *}$ \\ ${ }^{a}$ The Mary Nell and Ralph B. Rogers Magnetic Resonance Center, Department of Radiology, University of Texas Southwestern Medical Center, \\ Dallas, TX 75235, USA \\ ${ }^{\mathrm{b}}$ Center of Neurosciences and Department of Biochemistry, University of Coimbra, Coimbra, Portugal \\ ${ }^{\mathrm{c}}$ VA North Texas Health Care System, Dallas, TX 75216, USA \\ ${ }^{\mathrm{d}}$ Department of Chemistry, University of Texas at Dallas, Richardson, TX 75080, USA
}

Received 9 May 2003

\begin{abstract}
A triple-tracer method was developed to provide absolute fluxes contributing to endogenous glucose production and hepatic tricarboxylic acid (TCA) cycle fluxes in 24-h-fasted rats by ${ }^{2} \mathrm{H}$ and ${ }^{13} \mathrm{C}$ nuclear magnetic resonance (NMR) analysis of a single glucose derivative. A primed, intravenous $\left[3,4-{ }^{13} \mathrm{C}_{2}\right]$ glucose infusion was used to measure endogenous glucose production; intraperitoneal ${ }^{2} \mathrm{H}_{2} \mathrm{O}$ (to enrich total body water) was used to quantify sources of glucose (TCA cycle, glycerol, and glycogen), and intraperitoneal $\left[\mathrm{U}^{2}{ }^{13} \mathrm{C}_{3}\right]$ propionate was used to quantify hepatic anaplerosis, pyruvate cycling, and TCA cycle flux. Plasma glucose was converted to monoacetone glucose (MAG), and a single ${ }^{2} \mathrm{H}$ and ${ }^{13} \mathrm{C}$ NMR spectrum of MAG provided the following metabolic data (all in units of $\mu \mathrm{mol} / \mathrm{kg} / \mathrm{min} ; n=6)$ : endogenous glucose production (40.4 \pm 2.9$)$, gluconeogenesis from glycerol (11.5 \pm 3.5$)$, gluconeogenesis from the TCA cycle (67.3 \pm 5.6 ), glycogenolysis (1.0 \pm 0.8$)$, pyruvate cycling (154.4 \pm 43.4$)$, PEPCK flux (221.7 \pm 47.6$)$, and TCA cycle flux $(49.1 \pm 16.8)$. In a separate group of rats, glucose production was not different in the absence of ${ }^{2} \mathrm{H}_{2} \mathrm{O}$ and $\left[\mathrm{U}-{ }^{13} \mathrm{C}\right]$ propionate, demonstrating that these tracers do not alter the measurement of glucose turnover.
\end{abstract}

(c) 2004 Elsevier Inc. All rights reserved.

Keywords: Liver metabolism; Glucose turnover; Gluconeogenesis; NMR; Stable isotope tracers; Citric acid cycle

Measurements of whole-body glucose production $(\mathrm{GP})^{1}$ by dilution of intravenously infused labeled glucose are simple, in principle. Simultaneous measures of related metabolic fluxes involved in glucose production are far more challenging due to the various precursors available for glucose synthesis in vivo and their intimate links to acetyl-CoA oxidation and energy production by the TCA cycle. Multiple tracer molecules and experiments are required to obtain a comprehensive picture of

\footnotetext{
${ }^{*}$ Corresponding author. Fax: 1-214-883-2925.

E-mail address: sherry@utdallas.edu (A.D. Sherry).

${ }^{1}$ Abbreviations used: GP, glucose production; TCA, tricarboxylic acid; MAG, monoacetone glucose; PEP, phosphoenolpyruvic acid; OAA, oxaloacetate; PEPCK, phosphoenolpyruvate carboxykinase.
}

glucose production to the level of gluconeogenic TCA cycle substrates. These sophisticated studies typically combine measures of GP with contributions from glycogenolysis measured by in vivo magnetic resonance spectroscopy/imaging of hepatic glycogen [1], contributions from glycogen, glycerol, and the TCA cycle assessed by distribution of ${ }^{2} \mathrm{H}$ in plasma glucose [2-4], or distribution of ${ }^{13} \mathrm{C}$ in products of the TCA cycle [5-7].

Recent studies have emphasized the use of stable isotope tracers for quantifying glucose turnover and sources of glucose production because of convenience, safety, and ethical considerations for experiments with human subjects. Although mass spectrometry offers superior sensitivity [8], NMR may be better at resolving complex enrichment patterns which may involve more 
than one tracer (e.g., ${ }^{13} \mathrm{C}$ and $\left.{ }^{2} \mathrm{H}\right) \cdot{ }^{13} \mathrm{C}$ NMR also allows multiple ${ }^{13} \mathrm{C}$ tracers to be used if distinctive ${ }^{13} \mathrm{C}-{ }^{13} \mathrm{C}$ couplings are exploited in data analysis. For example, the combination of $\left[1,6-{ }^{13} \mathrm{C}_{2}\right]$ glucose, and $\left[\mathrm{U}_{-}{ }^{13} \mathrm{C}\right]$ propionate tracers coupled with ${ }^{13} \mathrm{C}$ NMR spectroscopy of plasma glucose provides a comprehensive picture of the fluxes at the level of pyruvate and the TCA cycle that support glucose production [9]. This mixture of ${ }^{13} \mathrm{C}$ tracers can be supplemented with an additional ${ }^{2} \mathrm{H}$ tracer, such as ${ }^{2} \mathrm{H}_{2} \mathrm{O}$, since, at low enrichment levels $(<4 \%)$, observation of the ${ }^{13} \mathrm{C}$ nucleus is not significantly perturbed by the presence of ${ }^{2} \mathrm{H}$ or vice versa. Thus, glucose enrichment and isotopomer patterns from a combination of $\left[1,6-{ }^{13} \mathrm{C}_{2}\right]$ glucose, $\left[\mathrm{U}_{-}{ }^{13} \mathrm{C}\right]$ propionate, and ${ }^{2} \mathrm{H}_{2} \mathrm{O}$ tracers was resolved by ${ }^{13} \mathrm{C}$ and ${ }^{2} \mathrm{H}$ NMR spectroscopy. The ${ }^{2} \mathrm{H}_{2} \mathrm{O}$ tracer resolves the contributions of glycogen, glycerol, and gluconeogenic Krebs cycle outflow to glucose production, thereby complementing the information from the ${ }^{13} \mathrm{C}$ tracers and providing a more complete description of glucose synthesis [4]. This method had one experimental annoyance in that $\left[1,6-{ }^{13} \mathrm{C}_{2}\right]$ glucose (to measure glucose turnover) could be quantified only in the native glucose sample while enrichment from the remaining ${ }^{2} \mathrm{H}_{2} \mathrm{O}$ and $\left[\mathrm{U}_{-}{ }^{13} \mathrm{C}\right]$ propionate tracers required conversion to monoacetone glucose (MAG) for analysis. ${ }^{2}$

Here, we introduce a simpler and faster method to estimate whole-body glucose turnover using [3,4${ }^{13} \mathrm{C}_{2}$ ]glucose as a tracer that may also be used in combination with ${ }^{2} \mathrm{H}_{2} \mathrm{O}$ and $\left[\mathrm{U}_{-}{ }^{13} \mathrm{C}\right]$ propionate. In this case, all plasma glucose is converted to MAG and a complete metabolic analysis is provided by one ${ }^{13} \mathrm{C}$ NMR spectrum and one ${ }^{2} \mathrm{H}$ NMR spectrum, thereby streamlining the analysis.

\section{Methods}

\section{Materials}

$\left[3,4-{ }^{13} \mathrm{C}_{2}\right]$ glucose $(99 \%)$ was purchased from Omicron Biochemicals (South Bend, IN). [U- ${ }^{13}$ C]propionate $(99 \%),{ }^{2} \mathrm{H}_{2} \mathrm{O}(99.9 \%)$, and deuterated acetonitrile (99.8\%) were obtained from Cambridge Isotopes (Andover, MA). DSC-18 solid-phase extraction gel was obtained from Supelco (St. Louis, MO). Other common chemicals were purchased from Sigma (St. Louis, MO).

${ }^{2}\left[1,6-{ }^{13} \mathrm{C}_{2}\right]$ glucose is resolved from $\left[1-{ }^{13} \mathrm{C}\right]$ and $\left[6-{ }^{13} \mathrm{C}\right]$ glucose as a result of long-range ${ }^{13} \mathrm{C}-{ }^{13} \mathrm{C}$ coupling between carbons 1 and 6 of $\beta$ glucose. On conversion to MAG, this coupling is abolished and the $\left[1,6-{ }^{13} \mathrm{C}_{2}\right]$ glucose tracer can no longer be resolved and quantified by ${ }^{13} \mathrm{C}$ NMR. Therefore, the method requires NMR analysis of glucose both before and after derivatization to MAG.

\section{Protocol}

The study was approved by the Institutional Animal Care and Use Committee. Male Sprague-Dawley rats weighing $211 \pm 26 \mathrm{~g}$ were fasted for $24 \mathrm{~h}$ with free access to water after which the jugular vein was cannulated under ketamine/xylazine anesthesia. Rats in group I $(n=6)$ received a bolus infusion of $3.5 \mathrm{mg}\left[3,4-{ }^{13} \mathrm{C}_{2}\right]$ glucose $(99 \%)$ followed by continuous infusion of $\left[3,4-{ }^{13} \mathrm{C}_{2}\right]$ glucose at $1.60 \mu \mathrm{mol} / \mathrm{min} / \mathrm{kg}$ for $90 \mathrm{~min}$. Rats in group II $(n=6)$ received an intraperitoneal injection of a solution $\left(20 \mu \mathrm{L} / \mathrm{g}\right.$ rat) containing $5 \mathrm{mg}$ of $\left[\mathrm{U}^{13}{ }^{13} \mathrm{C}\right]$ propionate $/ \mathrm{mL}$ ${ }^{2} \mathrm{H}_{2} \mathrm{O}$ followed by the same infusion of $\left[3,4-{ }^{13} \mathrm{C}_{2}\right]$ glucose as the group I rats. At the end of each infusion protocol, $\sim 8 \mathrm{~mL}$ of blood was drawn from the descending aorta and the liver was freeze-clamped with liquid $\mathrm{N}_{2}$.

\section{Sample processing}

Blood was immediately centrifuged and plasma supernatant was deproteinized by treatment with cold perchloric acid. After neutralization with $\mathrm{KOH}$ and centrifugation, the supernatant was lyophilized. To convert plasma glucose into MAG (Fig. 1), the dried residue was suspended in $3.0 \mathrm{~mL}$ of acetone containing $120 \mu \mathrm{L}$ of concentrated sulfuric acid. The mixture was stirred for $4 \mathrm{~h}$ at room temperature to yield diacetone glucose.

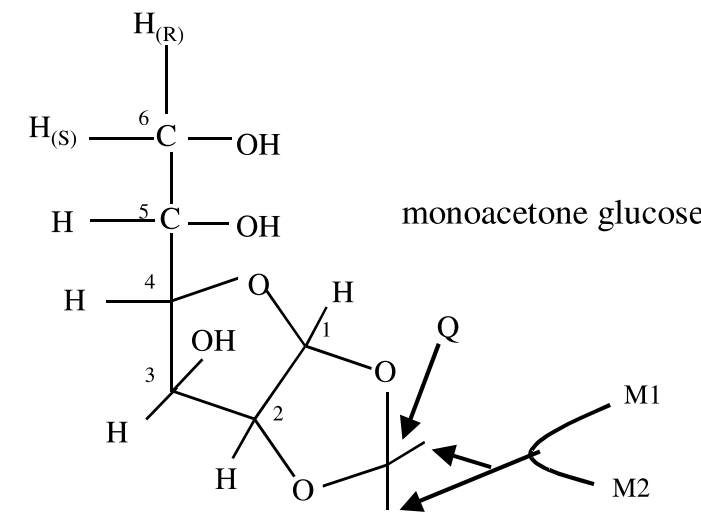

\begin{tabular}{lcc}
\hline Carbon & Chemical shift $(\mathrm{ppm})$ & $\mathrm{T}_{1}(\mathrm{sec})$ \\
\hline C1 & 105.6 & $4.0 \pm 0.3$ \\
C2 & 85.8 & $3.5 \pm 0.1$ \\
C3 & 75.3 & $3.4 \pm 0.1$ \\
C4 & 80.5 & $3.9 \pm 0.2$ \\
C5 & 70.2 & $3.6 \pm 0.2$ \\
C6 & 64.4 & $2.2 \pm 0.1$ \\
M1* & 26.1 & $1.8 \pm 0.1$ \\
M2* & 26.7 & $1.9 \pm 0.1$ \\
Q & 111.8 & $46.2 \pm 4.2$ \\
\hline
\end{tabular}

Fig. 1. $T_{1}$ values of MAG carbons for a sample dissolved in deuterated acetonitrile. The two methyl carbons are arbitrarily labeled M1 and M2 without regard to spatial arrangement in the molecule. 
After filtering off any remaining precipitate and adding $3 \mathrm{~mL}$ of water, the $\mathrm{pH}$ was adjusted 2.0 by dropwise addition of a $1.5 \mathrm{M} \mathrm{Na} \mathrm{CO}_{3}$ solution. The mixture was stirred for $24 \mathrm{~h}$ at room temperature to convert diacetone glucose into MAG. The $\mathrm{pH}$ was then further increased to 8.0 using $\mathrm{Na}_{2} \mathrm{CO}_{3}$ and the sample was dried. MAG was extracted $(5 \times)$ with $3 \mathrm{~mL}$ of hot ethyl acetate. These solutions were combined and the ethyl acetate was removed by vacuum evaporation. The resulting MAG was further purified by passage through a 3-mL Discovery DSC- 18 cartridge using 5\% acetonitrile as eluant. The effluent was freeze-dried and stored dry prior to NMR analysis.

Standard MAG samples $(\sim 22 \mu \mathrm{mol})$ were prepared by starting with known mixtures of natural abundance glucose and $\left[3,4-{ }^{13} \mathrm{C}_{2}\right]$ glucose $(0-7.84 \%)$. This amount was chosen based upon the total plasma glucose expected from a $\sim 200$-g rat.

\section{NMR spectroscopy}

${ }^{2} \mathrm{H}$ NMR spectra were collected using a Varian INOVA $14.1 \mathrm{~T}$ spectrometer (Varian Instruments, Palo Alto, CA) equipped with 3-mm broadband probe tuned to ${ }^{2} \mathrm{H}(92.1 \mathrm{MHz})$. MAG was dissolved in $90 \%$ acetonitrile $/ 10 \%$ water and shimming was performed on selected ${ }^{1} \mathrm{H}$ resonances of MAG detected via the decoupler ${ }^{1} \mathrm{H}$ coil. Proton-decoupled ${ }^{2} \mathrm{H}$ NMR spectra were acquired at $50^{\circ} \mathrm{C}$ using a $90^{\circ}$ pulse and a 1 -s acquisition time. Typically $6000-20,000$ scans were averaged. Proton decoupling was performed using a standard WALTZ-16 pulse sequence. ${ }^{2} \mathrm{H}$ NMR spectra were analyzed by Bayesian analysis [10].

These samples were then freeze-dried and redissolved in deuterated acetonitrile for ${ }^{13} \mathrm{C}$ NMR analysis. ${ }^{13} \mathrm{C}$ spectra were collected using the same spectrometer and probe with the observe coil tuned to ${ }^{13} \mathrm{C}(150 \mathrm{MHz}) \cdot{ }^{13} \mathrm{C}$ NMR spectra were collected using $52^{\circ}{ }^{13} \mathrm{C}$ pulse (the optimal Ernst angle; see Fig. 1 for relaxation times), a 1.5 -s acquisition time, and zero interpulse delay at $25^{\circ} \mathrm{C}$. Typically $4000-40,000$ scans were averaged. ${ }^{13} \mathrm{C}$ NMR spectra were analyzed using the curve-fitting routine supplied with NUTS PC-based NMR spectral analysis program (Acorn NMR Inc., Freemont, CA). Spin-lattice relaxation times $\left(T_{1}\right)$ were measured using a standard inversion recovery method. Typical parameters were a $90^{\circ}$ pulse width of $10.4 \mu \mathrm{s}$, an interpulse delay of $15.0 \mathrm{~s}$, and an average of 320 scans.

\section{Measurement of glucose turnover and metabolic fluxes}

Glucose turnover was measured by dilution of infused $\left[3,4-{ }^{13} \mathrm{C}_{2}\right]$ glucose by endogenous GP as measured in the ${ }^{13} \mathrm{C}$ NMR spectrum of MAG. The area of the doublet due to $J_{34}$ in carbon 3 (at $75.3 \mathrm{ppm}$ ) was defined as $A_{\mathrm{C} 3 \mathrm{D} 34}$, the area of the doublet due to $J_{34}$ in carbon 4 (at
$80.5 \mathrm{ppm})$ was defined as $A_{\mathrm{C} 4 \mathrm{D} 34}$, and the total area of the two methyl resonances (at 26.1 and $26.7 \mathrm{ppm}$ ) was defined as $A_{\text {methyl }}$. The fraction of a glucose sample that was $\left[3,4-{ }^{13} \mathrm{C}_{2}\right]$ glucose was determined from the ratio $\left(A_{\mathrm{C} 3 \mathrm{D} 34}+A_{\mathrm{C} 4 \mathrm{D} 34}\right) / A_{\text {methyl }}$ of MAG obtained from standard samples (Fig. 2). Samples of known standards showed a linear correlation between $\left[3,4-{ }^{13} \mathrm{C}_{2}\right]$ glucose enrichment and the ratio $\left(A_{\mathrm{C} 3 \mathrm{D} 34}+A_{\mathrm{C} 4 \mathrm{D} 34}\right) / A_{\text {methyl }}$ : $L=1.4278 x+0.0626$, where $L$ is the percentage of total glucose that is $\left[3,4-{ }^{13} \mathrm{C}_{2}\right]$ glucose and $x=\left(A_{\mathrm{C} 3 \mathrm{D} 34}+\right.$ $\left.A_{\mathrm{C} 4 \mathrm{D} 34}\right) / A_{\text {methyl }}\left(r^{2}=0.998\right)$. The two carbons of methyl groups (labeled M1 and M2 in Fig. 1) of MAG originated from natural abundance acetone introduced during the conversion of glucose to MAG.

Glucose production was calculated from the known infusion rate $\left(R_{\mathrm{i}}\right)$, the fraction of infusate glucose that was $\left[3,4-{ }^{13} C_{2}\right]$ glucose $\left(L_{\mathrm{i}}\right)$, and the fraction of plasma glucose that was $\left[3,4-{ }^{13} \mathrm{C}_{2}\right]$ glucose $\left(L_{\mathrm{p}}\right)$ :
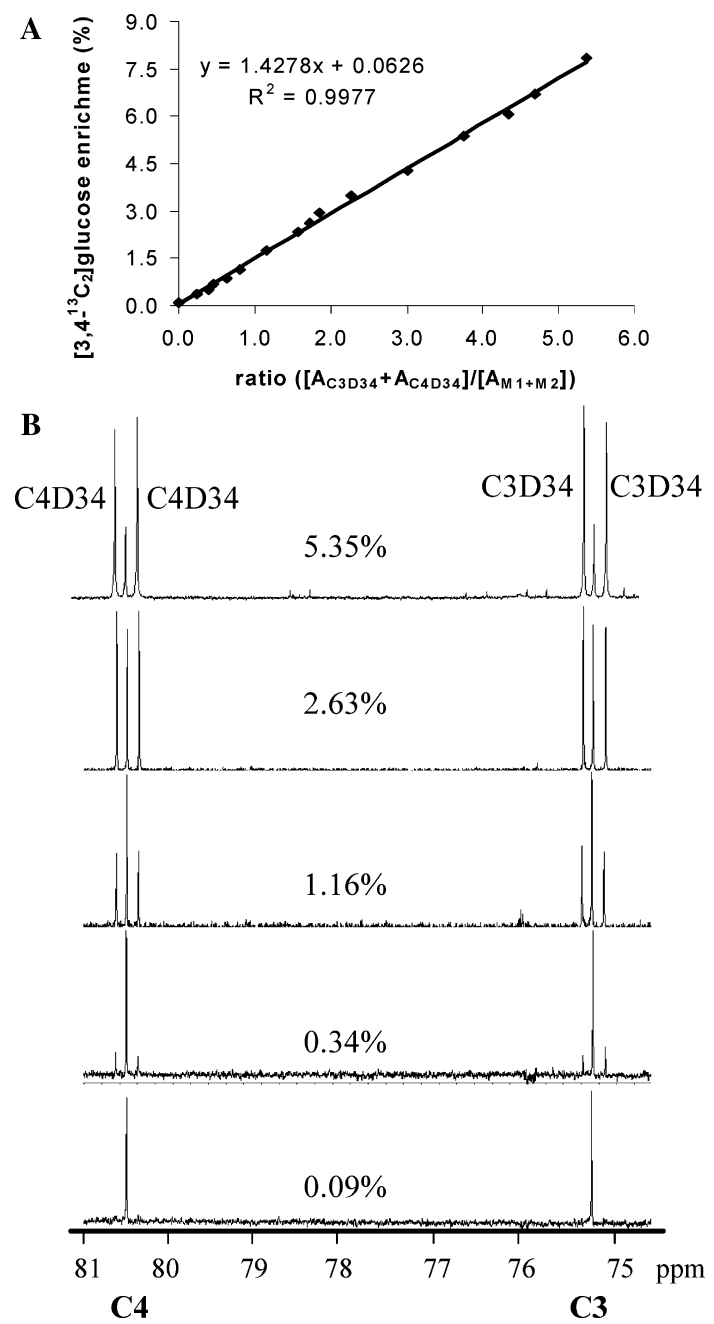

Fig. 2. Graph (A) of $\left[3,4-{ }^{13} \mathrm{C}_{2}\right]$ glucose enrichment vs ratio $\left(\left[A_{\mathrm{C} 3 \mathrm{D} 34}+\right.\right.$ $\left.\left.A_{\mathrm{C} 4 \mathrm{D} 34}\right] /\left[A_{\mathrm{M} 1}+A_{\mathrm{M} 2}\right]\right)$ measured using ${ }^{13} \mathrm{C}$ NMR spectra collected on a set of standard samples. Multiplets of $\mathrm{C} 3$ and $\mathrm{C} 4$ from several standard samples are shown (B). D34 represents the doublet arising from spinspin coupling of carbons 3 and 4 . 
$v_{1}=$ glucose production $=R_{\mathrm{i}} \cdot\left(L_{\mathrm{i}}-L_{\mathrm{p}}\right) / L_{\mathrm{p}}$.

Flux from glycogen, glycerol, and PEP into plasma glucose was estimated using ${ }^{2} \mathrm{H}$ NMR analysis of MAG based on the ratio of deuterium enrichment at positions 2,5 , and $6_{\mathrm{s}}$ as previously described [4]:

$v_{2}=$ flux from glycogen $=v_{1} \cdot(\mathrm{H} 2-\mathrm{H} 5) / \mathrm{H} 2$,

$v_{3}=$ flux from glycerol $=2 \cdot v_{1} \cdot\left(\mathrm{H} 5-\mathrm{H} 6_{\mathrm{s}}\right) / \mathrm{H} 2$,

and

$v_{4}=$ flux from $\mathrm{PEP}=2 \cdot v_{1} \cdot \mathrm{H} 6_{\mathrm{s}} / \mathrm{H} 2$.

$\mathrm{A}{ }^{13} \mathrm{C}$ NMR isotopomer analysis based on the ${ }^{13} \mathrm{C}-$ ${ }^{13} \mathrm{C}$ spin-coupled multiplets of $\mathrm{C} 2$ of MAG that yields relative fluxes in the citric acid cycle, $v_{4} / v_{7}=(\mathrm{Q}-\mathrm{D} 23) /$ $\mathrm{D} 23, v_{5} / v_{7}=(\mathrm{D} 12-\mathrm{Q}) / \mathrm{D} 23$, and $v_{6} / v_{7}=(\mathrm{D} 12-\mathrm{D} 23) /$ D23, has been reported previously [6]. On rearrangement,

$v_{5}=$ pyruvate cycling (flux through pyruvate kinase and malic enzyme)

$=v_{4} \cdot(\mathrm{D} 12-\mathrm{Q}) /(\mathrm{Q}-\mathrm{D} 23)$,

$v_{6}=$ flux through PEPCK

$=v_{4} \cdot(\mathrm{D} 12-\mathrm{D} 23) /(\mathrm{Q}-\mathrm{D} 23)$,

and

$v_{7}=$ flux through citrate synthase

$=v_{4} \cdot(\mathrm{D} 23) /(\mathrm{Q}-\mathrm{D} 23)$.

Pyruvate cycling refers to the combined flux through the malic enzyme and pyruvate kinase into the pyruvate pool, followed by pyruvate carboxylation to OAA and equilibration with the fumarate pool. The variables $\mathrm{C} 2 \mathrm{Q}$, C2D23, and C2D12 are the areas of the quartet; doublet due to $J_{12}$, and doublet due to $J_{23}$, relative to the area of the $\mathrm{C} 2$ resonance [6]. The assumptions in the metabolic model include no significant ${ }^{13} \mathrm{C}$ enrichment in acetyl$\mathrm{CoA}$, full equilibration of ${ }^{13} \mathrm{C}$ labeling patterns from OAA "backwards" into fumarate, and steady state metabolic conditions [6].

Results are reported as mean \pm 1 standard deviation.

\section{Results}

The longitudinal relaxation time and chemical shift of each MAG carbon resonance are summarized in Fig. 1. The $T_{1}$ values of all protonated MAG carbons were between $\sim 2$ and $4 \mathrm{~s}$ and these data were used to establish the optimal Ernst angle $\left(52^{\circ}\right)$ for a pulse repetition rate of $1.5 \mathrm{~s}$. Fig. 2 shows examples of ${ }^{13} \mathrm{C}$ NMR spectra from standard samples. Even at the low level of enrichments attempted in this experiment, $0.34 \%\left[3,4-{ }^{13} \mathrm{C}_{2}\right]$ glucose, one could accurately detect and measure the areas of the D34 resonances in a spectrum averaged over 4000 scans. The standard curve was linear over a broad range of $\left[3,4-{ }^{13} \mathrm{C}_{2}\right.$ ]glucose-excess enrichments with a high correlation coefficient $\left(y=1.4278 x+0.0626, x=\left[A_{\mathrm{C} 3 \mathrm{D} 34}+\right.\right.$ $\left.A_{\mathrm{C} 4 \mathrm{D} 34}\right] /\left[A_{\mathrm{M} 1}+A_{\mathrm{M} 2}\right], \quad y=\left[3,4-{ }^{13} \mathrm{C}_{2}\right]$ glucose enrichment, $\left.r^{2}=0.998\right)$. Although the areas of both methyl carbon resonances and both D34 resonances were used for the standard curve shown in Fig. 2, equally reliable data were obtained by analysis of only one resonance of each type (data not shown).

Fig. 3 shows a ${ }^{13} \mathrm{C}$ NMR spectrum of MAG derived from plasma glucose of a rat after infusion of [3,4${ }^{13} \mathrm{C}_{2}$ ]glucose alone. Again, the D34 resonances were well resolved $\left(J_{34}=37.8 \mathrm{~Hz}\right)$ and with measurement of those areas relative to the methyl resonances plus the standard curve of Fig. 2, a $\left[3,4-{ }^{13} \mathrm{C}_{2}\right]$ glucose enrichment of $L_{\mathrm{p}}=3.99 \pm 0.49 \%(n=6)$ was found. Given the known rate of glucose infusion in this group of rats $\left(R_{\mathrm{i}}=1.60 \mu \mathrm{mol} / \mathrm{kg} / \mathrm{min}\right)$ and the fraction of infused glucose that was $\left[3,4-{ }^{13} \mathrm{C}_{2}\right]$ glucose $\left(L_{\mathrm{i}}=99 \%\right)$, glucose production was calculated using Eq. (1). Those data along with plasma glucose levels are summarized in Table 1. Glucose turnover was also measured in a separate group of rats who had received a single IP injection of ${ }^{2} \mathrm{H}_{2} \mathrm{O}$ and $\left[\mathrm{U}_{-}{ }^{13} \mathrm{C}\right]$ propionate prior to infusion of $\left[3,4-{ }^{13} \mathrm{C}_{2}\right] \mathrm{glu}$ cose. Fig. 4 shows the expanded $\mathrm{C} 2$ and $\mathrm{C} 4$ resonances of MAG derived from plasma glucose from one such animal. Here, the ${ }^{13} \mathrm{C}$ NMR spectra are more complex due to the multiple ${ }^{13} \mathrm{C}$ tracers, yet the D34 multiplets arising from $\left[3,4-{ }^{13} \mathrm{C}_{2}\right]$ glucose were well resolved from all other MAG multiplets generated as a result of $\left[\mathrm{U}-{ }^{13} \mathrm{C}\right]$ propionate metabolism. This shows that

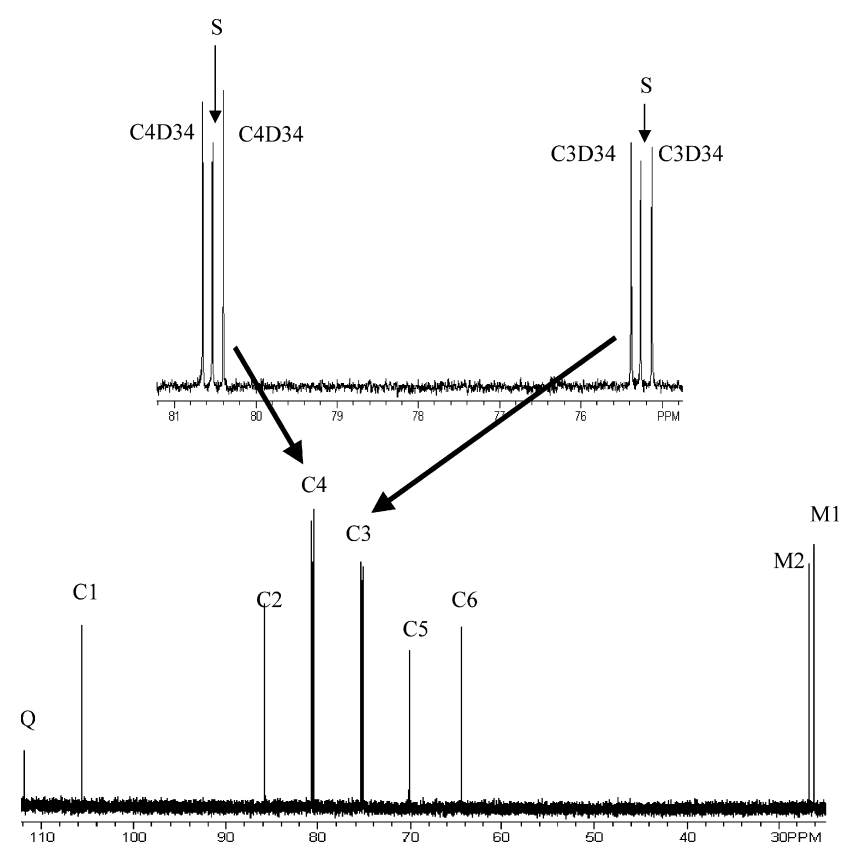

Fig. 3. ${ }^{13} \mathrm{C}$ NMR spectra of MAG converted from plasma glucose from a rat infused with $\left[3,4-{ }^{13} \mathrm{C}_{2}\right]$ glucose. Peak $Q$ is from the quaternary carbon of MAG while M1 and M2 are methyl resonances at natural abundance levels of ${ }^{13} \mathrm{C}$. $\left[3,4-{ }^{13} \mathrm{C}_{2}\right]$ glucose enrichment in this sample was estimated at $3.27 \%$ based upon the standard curve of Fig. 2. 
Table 1

Plasma glucose levels, excess enrichment of $\left[3,4-{ }^{13} \mathrm{C}_{2}\right]$ glucose in plasma glucose, and glucose production (GP) in two groups of 24-h-fasted rats

\begin{tabular}{lcc}
\hline & Group I & Group II \\
\hline$\left[3,4-{ }^{13} \mathrm{C}_{2}\right]$ glucose enrichment $(\%)$ & $3.99 \pm 0.49$ & $3.77 \pm 0.65$ \\
$\mathrm{GP}(\mu \mathrm{mol} / \mathrm{kg} / \mathrm{min})$ & $38.3 \pm 2.0$ & $40.4 \pm 2.9$ \\
Plasma glucose $(\mathrm{mM})$ & $5.5 \pm 0.4$ & $6.2 \pm 1.0$ \\
\hline
\end{tabular}

Group I $(n=6)$ received the single tracer $\left[3,4-{ }^{13} \mathrm{C}_{2}\right]$ glucose while group II $(n=6)$ received an intraperitoneal injection of $\left[\mathrm{U}-{ }^{13} \mathrm{C}\right]$ propionate $/{ }^{2} \mathrm{H}_{2} \mathrm{O}$ before infusion of $\left[3,4-{ }^{13} \mathrm{C}_{2}\right]$ glucose.

$\left[3,4-{ }^{13} \mathrm{C}_{2}\right]$ glucose does not interfere with isotopomer analysis of the $\mathrm{C} 2$ multiplets. Metabolism of [3,4${ }^{13} \mathrm{C}_{2}$ ]glucose at the level of the TCA cycle followed by resynthesis of glucose could occur, but this would have generated only isotopomers that contribute to the $\mathrm{C} 3$ singlet or the $\mathrm{C} 4$ singlet. Otherwise, the ${ }^{13} \mathrm{C}$ is lost in the citric acid cycle as $\mathrm{CO}_{2}$. Thus, the two ${ }^{13} \mathrm{C}$ tracers in this experiment provide completely independent metabolic data without interference from one another. The excess enrichment of $\left[3,4-{ }^{13} \mathrm{C}_{2}\right]$ glucose in plasma glucose in this group of animals was $3.77 \pm 0.65 \%(n=6)$. This reflects a glucose production rate of $40.4 \pm 2.9 \mu \mathrm{mol} /$ $\mathrm{kg} / \mathrm{min}$, not significantly different from the group of animals that did not receive ${ }^{2} \mathrm{H}_{2} \mathrm{O}$ and $\left[\mathrm{U}_{-}{ }^{13} \mathrm{C}\right]$ propionate $(38.3 \pm 2.0 \mu \mathrm{mol} / \mathrm{kg} / \mathrm{min})$.

A further isotopomer analysis of the $\mathrm{C} 2$ multiplets using Eqs. (5)-(7) provided a measure of flux through PEPCK, pyruvate cycling, and gluconeogenesis as summarized in Table 2. PEPCK flux (OAA $\rightarrow$ PEP) was high as expected for 24-h-fasted rats, about 4.6-fold higher than TCA cycle flux. Also, pyruvate cycling was found to be highly active, representing $\sim 70 \%$ of the PEP leaving the TCA cycle.

A ${ }^{2} \mathrm{H}$ NMR spectrum of the same MAG sample is also shown in Fig. 4. Using the areas of the H2, H5, and $\mathrm{H}_{\mathrm{s}}$ resonances and Eqs. (2)-(4), the contributions of glycogen, glycerol, and PEP to glucose production could be derived. These data (Table 2) show that PEP was the major contributor to GP ( $83 \%$ ), glycerol contributed $\sim 14 \%$, while none came from glycogen. These data are consistent with depletion of hepatic glycogen in rats after a $24-h$ fast [11].
A

$\mathrm{C} 4$

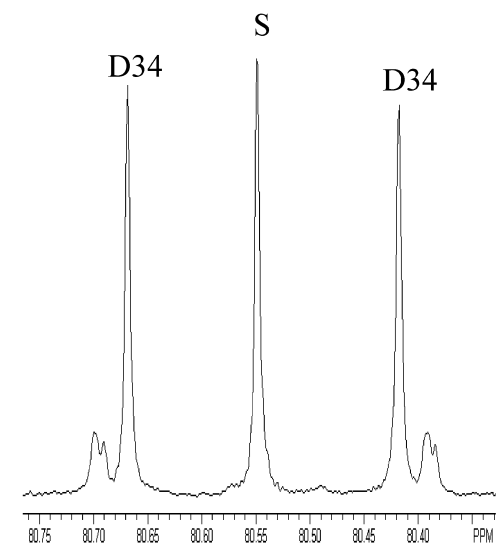

$\mathrm{C} 2$

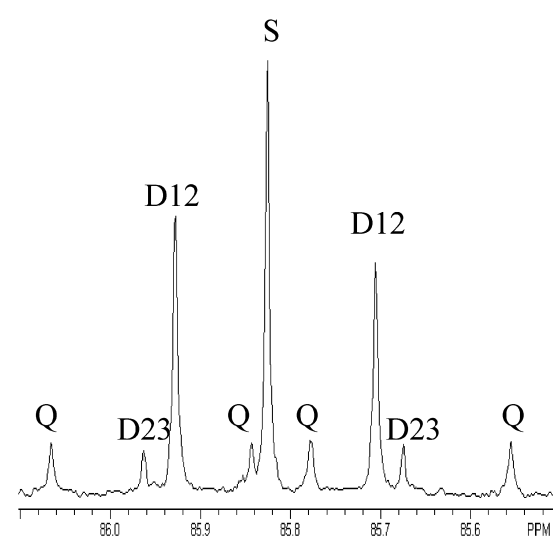

B

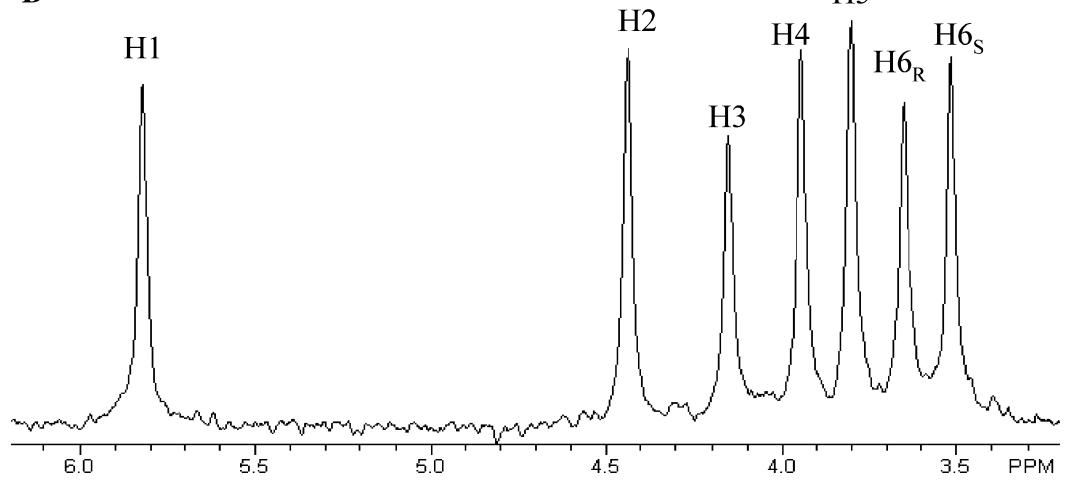

Fig. 4. Select resonances from the ${ }^{13} \mathrm{C}$ NMR spectrum (A) and ${ }^{2} \mathrm{H}$ NMR spectrum (B) of MAG derived from plasma glucose from a $24-\mathrm{h}-$ fasted rat after infusion of $\left[3,4-{ }^{13} \mathrm{C}_{2}\right]$ glucose and intraperitoneal injection of $\left[\mathrm{U}_{-}{ }^{13} \mathrm{C}\right]$ propionate and ${ }^{2} \mathrm{H}_{2} \mathrm{O}$. In ${ }^{13} \mathrm{C}$ NMR: D34, doublet from coupling of carbon 3 with carbon 4; D12, doublet from coupling of carbon 1 with carbon 2; D23 doublet from coupling of carbon 2 with carbon 3; Q, doublet of doublets, or quartet, arising from coupling of carbon 2 with both carbons 1 and 3; S, singlet resonance. In ${ }^{2} \mathrm{H}$ NMR spectrum, seven aliphatic hydrogens derived from plasma glucose are shown in the 3- to 6-ppm region. 
Table 2

Metabolic flux profile derived from a single ${ }^{2} \mathrm{H}$ NMR spectrum and a single ${ }^{13} \mathrm{C}$ NMR spectrum of monoacetone glucose (MAG derived from plasma glucose) from group II animals (see Table 1)

\begin{tabular}{lcc}
\hline Pathway & Relative flux & $\begin{array}{c}\text { Absolute flux } \\
(\mu \mathrm{mol} / \mathrm{kg} / \mathrm{min})\end{array}$ \\
\hline $\begin{array}{l}\text { Sources of glucose production } \\
\text { Glycogen } \rightarrow \text { glucose }\end{array}$ & $0.03 \pm 0.02$ & \\
Glycerol $\rightarrow$ glucose & $0.14 \pm 0.04$ & $1.0 \pm 0.8$ \\
$\quad$ (triose unit) & & $11.5 \pm 3.5$ \\
PEP $\rightarrow$ glucose & $0.83 \pm 0.03$ & $67.3 \pm 5.6$ \\
$\quad$ (triose unit) & & \\
Fluxes related to the $T C A$ & cycle $\left(\right.$ from $^{13}$ C NMR analysis $)$ \\
OAA $\rightarrow$ PEP & $4.65 \pm 0.62$ & $221.7 \pm 47.6$ \\
Pyruvate cycling & $3.19 \pm 0.44$ & $154.4 \pm 43.4$ \\
PEP $\rightarrow$ glucose & $1.46 \pm 0.32$ & $67.3 \pm 5.6$ \\
OAA $\rightarrow$ citrate & 1 & $49.1 \pm 16.8$ \\
\hline
\end{tabular}

Four carbon intermediates which exit the TCA cycle via either malic enzyme or PEPCK may reenter the cycle through the pyruvate pool. This process, termed pyruvate cycling, is the sum of fluxes through pyruvate kinase and malic enzyme.

Table 2 summarizes all relative and absolute metabolic fluxes that can be derived from a single sample of MAG from rats presented with the combination of three tracers, $\left[3,4-{ }^{13} \mathrm{C}_{2}\right]$ glucose, ${ }^{2} \mathrm{H}_{2} \mathrm{O}$, and $\left[\mathrm{U}-{ }^{13} \mathrm{C}\right]$ propionate. The absolute fluxes were obtained by integration of GP values with the relative fluxes derived from ${ }^{2} \mathrm{H}$ and ${ }^{13} \mathrm{C}$ NMR spectra. This provided a rather complete picture of metabolic fluxes in these animals (all in units of $\mu \mathrm{mol} /$ $\mathrm{kg} / \mathrm{min}$ ): gluconeogenesis from glycerol (11.5 \pm 3.5$)$, gluconeogenesis from the TCA cycle $(67.3 \pm 5.6)$, glycogenolysis $(1.0 \pm 0.8)$, pyruvate cycling $(154.4 \pm 43.4)$, PEPCK flux $(221.7 \pm 47.6)$, and TCA cycle flux $(49.1 \pm 16.8)$.

\section{Discussion}

We describe here a simple NMR method to obtain a comprehensive profile of hepatic metabolism using two ${ }^{13} \mathrm{C}$ tracer molecules, ${ }^{2} \mathrm{H}_{2} \mathrm{O}$, and collection of a single sample of plasma glucose. $\left[3,4-{ }^{13} \mathrm{C}_{2}\right]$ glucose proved to be a novel tracer to measure GP. We previously reported a similar method that used $\left[1,6-{ }^{13} \mathrm{C}_{2}\right]$ glucose [4] but this required significantly more data collection than the present method. The previous method required a measurement of ${ }^{13} \mathrm{C}$ fractional enrichment by ${ }^{1} \mathrm{H}$ NMR spectroscopy and this is subject to significant error due to the small intensities of the ${ }^{13} \mathrm{C}$ satellite peaks. In the present method, the methyl carbons of MAG containing natural abundance levels of ${ }^{13} \mathrm{C}$ were conveniently used as an internal reference standard for estimating excess enrichment of $\left[3,4-{ }^{13} \mathrm{C}_{2}\right]$ glucose in plasma glucose from a single ${ }^{13} \mathrm{C}$ NMR spectrum of MAG.

GP was identical in animals that received [3,4${ }^{13} \mathrm{C}_{2}$ ]glucose as the only exogenous substrate (group I, $38.3 \pm 2.0 \mu \mathrm{mol} / \mathrm{kg} / \mathrm{min}$ ) compared to animals that received an i.p. injection of $\left[\mathrm{U}_{-}{ }^{13} \mathrm{C}\right]$ propionate and ${ }^{2} \mathrm{H}_{2} \mathrm{O}$ prior to infusion of $\left[3,4-{ }^{13} \mathrm{C}_{2}\right]$ glucose (group II, $40.4 \pm 2.9 \mu \mathrm{mol} / \mathrm{kg} / \mathrm{min}$ ). This demonstrates that propionate and ${ }^{2} \mathrm{H}_{2} \mathrm{O}$ delivered at these levels and by this method do not alter glucose homeostasis. In a previous study wherein both propionate and $\left[1,6-{ }^{13} \mathrm{C}_{2}\right]$ glucose $(25$ and $2.75 \mu \mathrm{mol} / \mathrm{min} / \mathrm{kg}$, respectively) were infused into rats for $120 \mathrm{~min}$, a significantly higher glucose production rate $(56 \pm 2 \mu \mathrm{mol} / \mathrm{kg} / \mathrm{min})$ was found [9]. This apparent discrepancy could reflect the greater amount of $\left[\mathrm{U}-{ }^{13} \mathrm{C}\right]$ propionate received in the infusion protocol (a total of $825 \mu \mathrm{mol}$ was given over the 120 -min infusion period versus only $222 \mu \mathrm{mol}$ given here by bolus). This notwithstanding, a rather broad range of GP values for fasted rats has been reported $(32-67 \mu \mathrm{mol} / \mathrm{min} / \mathrm{kg})$ as measured by a variety of techniques [12-15]. GP in this work is in close agreement with values reported by Saadatian et al. [12] and Neese et al. [14] as determined by mass spectrometry.

Relative fluxes of PEP $\rightarrow$ glucose, OAA $\rightarrow$ PEP, and pyruvate cycling to the TCA flux were consistent with our previous measurement for 24 -h-fasted rats using [U${ }^{13}$ C]propionate [9]. Absolute fluxes related to TCA cycle were lower than those in the previous report, largely because the earlier study assumed that all glucose was produced from PEP; i.e., neither glycogen nor glycerol contributed to glucose production. The current results and those of earlier reports indicate that glycerol makes a modest but measurable contribution to glucose production [16] and must be included in calculation of citrate synthase flux using the methods described here. By comparison, using $\left[{ }^{13} \mathrm{C}\right]$ lactate as a tracer, Katz et al. [13] found that flux through citrate synthase was $\sim 42 \mu \mathrm{mol} /$ $\mathrm{kg} / \mathrm{min}$ which agrees well with the current finding of $49.1 \pm 16.8 \mu \mathrm{mol} / \mathrm{kg} / \mathrm{min}$ (Table 2 ). TCA cycle flux is a direct measure of hepatic fatty acid oxidation if (as is commonly assumed) gluconeogenesis after a brief fast is largely hepatic and the bulk of acetyl-CoA entering the hepatic TCA cycle is derived from fat oxidation.

In our infusion protocol, the infusion rate of $1.60 \mu \mathrm{mol} / \mathrm{kg} / \mathrm{min}$ resulted in $\sim 4 \% \quad\left[3,4-{ }^{13} \mathrm{C}_{2}\right]$ glucose enrichment. Since $\sim 1 \%$ enrichment resulted in excellent signal-to-noise ratio for $\mathrm{C} 3$ and $\mathrm{C} 4$ multiplets by ${ }^{13} \mathrm{C}$ NMR (Fig. 2), the infusion rate could likely be significantly reduced without compromising the measurement. The infusion period is also subject to modification. The infusion period, $90 \mathrm{~min}$ following a prime injection, was considered adequate to reach steady state. In a single animal, $\left[3,4-{ }^{13} \mathrm{C}_{2}\right]$ glucose was infused for $150 \mathrm{~min}$ and analysis of plasma glucose from that animal gave the same glucose turnover rate as that reported here for a 90-min infusion period (data not shown). It may be possible to shorten the infusion period even further because earlier reports indicate that steady state was achieved after a primed 60 -min infusion in rats [12,17]. However, significantly longer periods may be required for human studies [18]. 
The combined use of ${ }^{13} \mathrm{C}$ NMR together with ${ }^{2} \mathrm{H}$ NMR to simultaneously detect the glucose tracer, relative fluxes in the TCA cycle, and relative rates of glycogenolysis and gluconeogenesis is potentially a powerful probe of systemic carbohydrate metabolism. The assumptions underlying the ${ }^{2} \mathrm{H}$ NMR analysis were described elsewhere $[4,19]$. The ${ }^{13} \mathrm{C}$ NMR analysis of the TCA cycle further requires that equilibration of oxaloacetate with fumarate is complete and that ${ }^{13} \mathrm{C}$ enrichment in acetyl-CoA is negligible [4,6]. If $5 \%$ of oxaloacetate does not pass through the fumarase reaction, as reported by Magnusson et al. [20] for fasted humans, then an error of about $15 \%$ will be introduced into pyruvate cycling. Entry of carbon tracer from the TCA cycle into acetyl-CoA was minimal $[4,20]$ in earlier studies but, under different metabolic conditions, acetyl-CoA enrichment could become significant, which would reduce the accuracy of these measurements involving the citric acid cycle. The accuracy of these measurements also depends on the quantitative precision of the NMR spectra. Since the multiplet measurements are correlated with one another, the effect of measurement error was evaluated in simulations over a physiological range of metabolic conditions with addition of random error to the simulated spectra. A $3 \%$ error in the ${ }^{13} \mathrm{C}$ NMR multiplets resulted in a $10 \%$ error in PEPCK flux and pyruvate cycling but less than a $2 \%$ error in citrate synthase flux.

In conclusion, we presented a simple method to measure glucose turnover with $\left[3,4-{ }^{13} \mathrm{C}_{2}\right]$ glucose using a ${ }^{13} \mathrm{C}$ NMR method. This method provides a complete liver flux profile when integrated with ${ }^{2} \mathrm{H}_{2} \mathrm{O}$ and [U${ }^{13} \mathrm{C}$ ]propionate tracers plus a single ${ }^{2} \mathrm{H}$ and ${ }^{13} \mathrm{C}$ NMR spectrum of MAG. We demonstrated its application with 24-h-fasted rats by providing comprehensive metabolic fluxes. This technique can be easily extended for metabolic flux measurements in human studies.

\section{Acknowledgments}

This study was supported by grants from the National Institutes of Health (RR-02584, DK16194, and HL-34557). Charles Storey and Angela Milde provided outstanding technical assistance.

\section{References}

[1] K.F. Petersen, T. Price, G.W. Cline, D.L. Rothman, G.I. Shulman, Contribution of net hepatic glycogenolysis to glucose production during the early postprandial period, Am. J. Physiol. 270 (1996) E186-E191.

[2] V. Chandramouli, K. Ekberg, W.C. Schumann, S.C. Kalhan, J. Wahren, B.R. Landau, Quantifying gluconeogenesis during fasting, Am. J. Physiol. Endocrinol. Metab. 273 (1997) E1209-E1215.
[3] G. Boden, X. Chen, E. Capulong, M. Mozzoli, Effects of free fatty acids on gluconeogenesis and autoregulation of glucose production in type 2 diabetes, Diabetes 50 (2001) 810-816.

[4] J.G. Jones, M.A. Solomon, S.M. Cole, A.D. Sherry, C.R. Malloy, An integrated ${ }^{2} \mathrm{H}$ and ${ }^{13} \mathrm{C}$ NMR study of gluconeogenesis and TCA cycle flux in humans, Am. J. Physiol. Endocrinol. Metab. 281 (2001) E848-E856.

[5] B.R. Landau, J. Wahren, K. Ekberg, S.F. Previs, D. Yang, H. Brunengraber, Limitations in estimating gluconeogeneiss and Cori cycling from mass isotopomer distributions using $\left[\mathrm{U}-{ }^{13} \mathrm{C}_{6}\right.$ ]glucose, Am. J. Physiol. 274 (1998) E954-E961.

[6] J.G. Jones, R. Naidoo, A.D. Sherry, F.M. Jeffrey, G.L. Cottam, C.R. Malloy, Measurement of gluconeogenesis and pyruvate cycling in the rat liver: a simple analysis of glucose and glutamate isotopomers during metabolism of $\left[1,2,3-{ }^{13} \mathrm{C}_{3}\right]$ propionate, FEBS Lett. 412 (1997) 131-137.

[7] J.A. Tayek, J. Katz, Glucose production, recycling, Cori cycle, and gluconeogenesis in humans: relationship to serum cortisol, Am. J. Physiol. 272 (1997) E476-E484.

[8] F.M. Jeffrey, J.S. Roach, C.J. Storey, A.D. Sherry, C.R. Malloy, ${ }^{13}$ C isotopomer analysis of glutamate by tandem mass spectrometry, Anal. Biochem. 300 (2002) 192-205.

[9] J.G. Jones, R.A. Carvalho, B. Franco, A.D. Sherry, C.R. Malloy, Measurement of hepatic glucose output, Krebs cycle, and gluconeogenic fluxes by NMR analysis of a single plasma glucose sample, Anal. Biochem. 263 (1998) 39-45.

[10] M. Merritt, G.L. Bretthorst, S.C. Burgess, A.D. Sherry, C.R. Malloy, Sources of plasma glucose by automated Bayesian analysis of ${ }^{2}$ H NMR Spectra, Mag. Res. Med. 50 (2003) 659-663.

[11] J. Katz, P.A. Wals, W.N. Lee, Determination of pathways of glycogen synthesis and the dilution of the three-carbon pool with [U- ${ }^{13}$ C]glucose, Proc. Natl. Acad. Sci. USA 88 (1991) 2102-2107.

[12] M. Saadatian, O. Peroni, F. Diraison, M. Beylot, In vivo measurement of gluconeogenesis in animals and humans with deuterated water: a simplified method, Diabetes Metab. 26 (2000) 202-209.

[13] J. Katz, P. Wals, W.N. Lee, Isotopomer studies of gluconeogenesis and the Krebs cycle with ${ }^{13} \mathrm{C}$-labeled lactate, J. Biol. Chem. 268 (1993) 25509-25521.

[14] R.A. Neese, J.-M. Schwarz, D. Faix, S. Turner, A. Letscher, D. Vu, M.K. Hellerstein, Gluconeogenesis and intrahepatic triose phosphate flux in response to fasting or substrate loads, J. Biol. Chem. 270 (1995) 14452-14463.

[15] K.F. Petersen, G.W. Cline, J.B. Blair, G.I. Shulman, Substrate cycling between pyruvate and oxaloacetate in awake normal and 3,3'-5-triiodo-L-thyronine-treated rats, Am. J. Physiol. 267 (1994) E273-E277.

[16] O. Peroni, V. Large, F. Diraison, M. Beylot, Glucose production and gluconeogenesis in postabsorptive and starved normal and streptozotocin-diabetic rats, Metabolism 46 (1997) 1358-1363.

[17] L. Rossetti, D. Smith, G.I. Shulman, D. Papachristou, R.A. DeFronzo, Correction of hyperglycemia with phlorizin normalizes tissue sensitivity to insulin in diabetic rats, J. Clin. Invest. 79 (1987) 1510-1515.

[18] S.K. Tigas, A.L. Sunehag, M.W. Haymond, Impact of duration of infusion and choice of isotope label on isotope recycling in glucose homeostasis, Diabetes 51 (2002) 3170-3175.

[19] B.R. Landau, J. Wahren, V. Chandramouli, W.C. Schumann, K. Ekberg, S.C. Kalhan, Use of ${ }^{2} \mathrm{H}_{2} \mathrm{O}$ for estimating rates of gluconeogenesis. Application to the fasted state, J. Clin. Invest. 95 (1995) 172-178.

[20] I. Magnusson, W.C. Schumann, G.E. Bartsch, V. Chandramouli, K. Kumaran, J. Wahren, B.R. Landau, Noninvasive tracing of Krebs cycle metabolism in liver, J. Biol. Chem. 266 (1991) 69756984. 